\title{
Alpha-fetoprotein: A fabulous biomarker in hepatocellular, gastric and rectal cancer diagnosis.
}

\author{
Zara Naz, Sana Usman, Komal Saleem, Sara Ahmed, Hamid Bashir, Muhammad Bilal, Aleena Sumrin* \\ Center for Applied Molecular Biology, University of the Punjab, 87-West Canal Bank Road, Lahore, Pakistan
}

\begin{abstract}
Elevated level of Alpha-Fetoprotein (AFP) has proved to be a golden ticket to track down tumors and various cancers such as Hepatocellular Carcinomas (HCC), Gastric (GC) and colorectal cancers. In hepatocellular carcinoma patients AFP serum concentrations of $400-500 \mathrm{ng} / \mathrm{ml}$ are determined to be diagnostic. Moreover, the prevalence of AFP induced gastric cancer ranges between 1.3-15\% among all gastric cancers. In all these cancers, AFP has displayed a dual role in tumor growth; it acts as a growth mediator as well as growth suppressant. This feature of AFP has been employed in production of AFP conjugated anti-cancerous drugs and is discussed in this review. This review throws light on role of AFP in hepatocellular, colorectal and gastric carcinomas.
\end{abstract}

Keywords: Alpha-fetoprotein, Hepatocellular carcinoma, Gastric cancer, Rectal cancer, Endocytosis, Tumor.

Accepted on August 28, 2017

\section{Introduction}

Alpha-fetoprotein is a multi-functional glycoprotein biomarker. It is one of the five members of albuminoid protein family. It plays diverse roles in prenatal diagnosis where it helps to find fetal birth defects. On the other hand it has potential to diagnose tumors and cancer growth.

AFP is a 591 amino acids glycoprotein encoded by AFP gene present on long arm of chromosome number 4 (4q25). Gitlin et al. first observed that AFP is produced by the fetus yolk sac and liver cells during fetal development. Its elevated level is indicative of neural tube defects, ataxia telangiectasia, yolk sac tumors and various other malignancies [1-3]. AFP protein has capacity to bind and transport dyes, heavy metals, steroids and fatty acids. AFP also regulates retinoids, flavinoids and phytoestrogens in the body. It is also involved in the delivery of variety of other ligands including organic drugs. This feature of AFP makes it a potent biomarker in studying the effect of various drugs on tumor growth [4].

AFP is a potent tumor biomarker in diagnosis of liver, breast, gastric, rectal, prostate and ovarian cancer. More than $70 \%$ of liver cancer patients show elevated level of serum AFP. The reference value of AFP is less than $6 \mathrm{ng} / \mathrm{ml}$. Various commercial tests are available to diagnose the elevated level of AFP in cancer patients. GP3 combined with AFP biomarker detects hepatocellular carcinomas with a sensitivity of $82 \%$ [5].

The purpose of this review is to convey the knowledge about the structure and functional diversities of this potent protein biomarker. In this review the main focus is on the role of AFP in hepatocellular carcinomas, gastric and rectal cancers and uses of AFP in diagnosis, growth regulation and treatment of tumors are also briefly reviewed.

\section{Structure}

The diversity of functions of alpha-fetoprotein is due to its specific structure and conformation. This glycoprotein biomarker comprises of a single chain whose molecular mass vary depending on the length of carbohydrate chain conjugated to it. However, its average molecular mass is 69 kilo-Dalton. The functional protein molecule has a v-shaped domain that is formed by repeated folding of the single-chain into loops. There are thirty-two cysteine amino-acid residues that helped in disulfide bridge formation to aid looping of chain. Unlike its other protein family members, it possesses specie specific variable length $\mathrm{CHO}$ side chain Figure 1 [6]. There is only glycan molecule at $\mathrm{N}$ - terminal, present on domain 2 of HAFP at amino acid arginine and this provides a binding site for lectin molecules and thus these aids in identification of tumors via lectin affinity electrophoresis [7].

\section{Biologically Important in Tumor Regulation}

The biological activities of alpha-fetoprotein involve the uptake of fatty acid and lipoproteins by monocytes, tumor cells and hepatocytes. In breast cancer, lymphoma cells and hepatocellular carcinoma it has been associated with regulation of cancer and angiogenesis. In uterine cells it is also involved in estrogen induced growth suppression and also known to affect the ovarian functions [8].

In healthy humans the normal value of this biomarker is calculated to be $5-8 \mathrm{ng} / \mathrm{ml}$. In a variety of tumors in both mice 
and humans, more than normal value of alpha-fetoprotein has been detected in serum. Majorly elevated level has been observed in liver carcinomas. However, abnormally high level of it is also seen in gastric tumors in stomach, ovary yolk sac tumors, testicular tumors, pancreatic tumors, gallbladder cancers, Barrett's adenocarcinoma and pulmonary carcinomas.
AFP secreted from any of these tumors can be easily detected and tell us about the tumor site as AFP is tumor specific both qualitatively and quantitatively [9-11].

Table 1 shows contributions by various researchers.

Table 1. Major discoveries of association of AFP in different cancers.

\begin{tabular}{ll}
\hline Authors & Major contribution \\
\hline Abelev et al. [12,13] & Discovery of AFP in mouse hematomas \\
\hline Tatarinov et al. [14] & Discovery of AFP in human liver cancer \\
\hline Bourreille et al. [15] & AFP and gastric cancer \\
\hline Mehleman et al. [16] & Association of AFP with prostatic cancer \\
\hline Mclntire et al. [17] & $\begin{array}{l}\text { Elevated levels of AFP in neoplasmas of gastric and intestinal track including pancreatic, colorectal and biliary tract } \\
\text { carcinomas }\end{array}$ \\
\hline Villacampa et al., Torre et al. [18,19] & Discovery of receptors for AFP in breast cancer and in T lymphoma cell lines \\
\hline Mizejewski and MacColl et al. [20] & Role of AFP inhibitory peptides for treatment of cancers
\end{tabular}

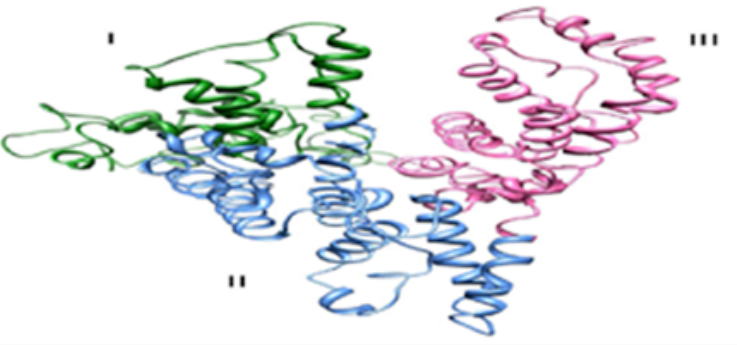

Figure 1. Structure of human AFP. Alpha-helices structures represent secondary elements.

\section{Endocytosis of AFP by Tumors}

AFP in tumor tissues is present in bound state, conjugated to other proteins and also secreted in circulatory system. In vitro and in vivo systems developed to see the uptake of AFP by tumor cells have shown positive results. Tumors of muscle tissues show endocytosis of AFP parallel to fetal and neonatal muscle tissues. As tumor cells like fetal endodermal, ectodermal and mesodermal cells are yet not differentiated, so it is concluded that AFP uptake occurs only in undifferentiated cells and neoplastic cells. Followed by uptake, its presence has been pointed by radio-imaging in cell membrane invaginations and golgi bodies network that surrounds the nucleus [8].

\section{Undifferentiated Cells Displaying AFP Receptors}

This uptake of AFP by normal and tumor cells is mediated by specific receptors present on cell membrane. The cancerous cells showing receptors of AFP reflect that they are incompletely mature or have become undifferentiated that is why they are displaying receptors for a protein taken up only by undifferentiated cells. On monocytes cells, the receptors of
AFP were first discovered, isolated and characterized but before that its receptor was reported by a doctoral thesis to be present on human breast cancer cell's membrane in 1991. Breast cancer, hepatocellular carcinomas, lymphomas, pulmonary tumors, uterine, brain, malenoma tumors display various scavenger receptors of AFP such as LOX-1, SCRA1, DSRC1, CXCL16 and stabilin. AFP binds to a wide variety of receptors of high, moderate and low affinity. AFP binding sites on receptors which are in the form of a hetrotrimer complex with molecular mass 250-300 kD has been discovered. The endocytosis of AFP through AFP receptors is an endocrine process; the AFP transports ligands which are needed for growth by malignant cells. This endocrine process of growth stimulation by AFP reaches maximum stage during exponential phase of tumor cells division. So, it's a trait of tumor cells to show transitory expression of receptors for AFP [21-23].

\section{Down Regulation of Tumor Growth by Aid of AFP}

The growth stimulated and regulated by AFP is by any of three processes: apoptosis, cytoplasmic signaling and G-coupled receptors signal transduction. Certain concentrations of AFP though increase the growth of tumors under specific concentrations as well as its low concentrations also minimize tumor size. However, AFP can also down regulate the growth by certain conformational alterations brought in it. Presence of other hormones, growth factors, and cytokines also triggers AFP to inhibit tumor growth. For example, in the presence of excess concentration of growth factor estradiol, AFP is converted into a growth suppressant molecule by certain changes brought in it by incubation with estradiol and is known to suppress the breast tumors and MCF-7 cells growth. The third domain of AFP molecule, named P149, has the ability of growth suppression. This region, from amino acid number 
447-480, is exposed to perform its function by incubation of AFP with steroids. A small concentration of AFP occurs naturally in this transformed version in our body. The synthetic form of this segment of AFP, also showed positive results when applied in vitro to suppress growth of a variety of tumors such as breast tumor, leukemia, adeno carcinoma and renal carcinomas $[24,25]$.

\section{AFP Role in Hepatocellular Carcinoma}

Hepatocellular carcinoma is the third major kind in cancer related deaths and fifth most commonly occurring tumor. Around the world, about 600,000 deaths due to HCC are reported [26]. To date; tremendous research is done to study molecular and pathological events leading to hepatocellular carcinoma. The dire need to diagnose HCC has led to the development of several methods to diagnose the disease. The most acceptable, commonly used and gold standard biomarker to correlate HCC is Alpha Fetoprotein (AFP). Since 1970's AFP has served as a diagnostic test for HCC, the time when people were diagnosed at very late stage of the indicated by clinical symptoms.

Alpha-fetoprotein is over expressed in HCC. For this reason, this represents one of the most useful markers for hepatocellular carcinoma. In addition to diagnosis, it has significance in monitoring the response of patient under therapy. According to earlier study, AFP has immunosuppressive properties, it induces production of spontaneous $\mathrm{T}$ and $\mathrm{B}$ cells responses in HCC patients. The immunogenic epitopes of AFP helps to generate antibodies as cancer vaccines for human HCC. The activity of AFP based vaccines has been tested upon mouse models to establish treatment strategies for HCC patients [27].

The increased values of AFP in HCC may not be a condition always. Sometimes, in earlier stages of HCC, AFP levels show an increased value and drop down later during its progression. In addition to this, elevated AFP values have been associated not only to acute and chronic viral Hepatitis, but also to patients with cirrhosis in Hepatitis C. Elevating values of AFP show correlation to cases with known prognostic values known risk factors such as cirrhosis [28]. As per regular diagnosis, ultrasound at intervals of 6-12 months along with observation of AFP serum concentration is beyond perfect. AFP serum concentrations of $400-500 \mathrm{ng} / \mathrm{ml}$ are determined to be diagnostic in this case [29], however, only in some cases, such greater values are observed. Unfortunately, observations of these estimated values do not always associate with prognosis of HCC, cirrhosis stage and tumor size. Moreover, ethnicity may also impart variability. Furthermore, cases of HCC are reported, where AFP elevations are not apparent at all [28].

Alpha-fetoprotein on the basis of their binding ability to lectin Lens Culinaris Agglutinin (LCA) is usually divided into three different glycoforms, AFP-L1, AFP-L2, and AFP-L3. Out of these, elevate levels of AFP-L3 has shown a relation to tumor masses, malignant characteristics and up-regulated liver function [30].
AFP has been mainly used as diagnostic factor rather than post treatment HCC surveillance observation. According to a study, in previously un-identified cases, AFP along with Ultrasounds (US) have shown to provide detection in $6-8 \%$ cases [31]. In Europe and USA, AFP has been defined as a variable in HCC diagnosis flowcharts [32,33].

\section{AFP Role in Gastric Cancers}

Alpha-Fetoprotein (AFP) is also reported for producing gastric cancer. It was first observed by Bourreille in 1970 [15]. AFP causes stimulatory effect on cell proliferation by inhibiting apoptosis [34]. The site AFP in gastric cancer cells can be detected by immunofluorescent technique [35]. The prevalence of AFP-GC ranges between 1.3-15\% among all gastric cancers [36,37]. It has two subtypes, non-hepatoid and hepatoid adenocarcinoma. In hepatoid subtype, there is liver type binding pattern of cells with large production of AFP. The normal serum level of AFP in body is $<12.00 \mathrm{ng} / \mathrm{ml} \mathrm{[38].}$ Correlation of increased level of serum AFP with hepatoid adenocarcinoma of stomach has been observed [39]. So quantification of AFP isotypes can be used for differentiating both types. Moreover both subtypes also differ on the basis morphological and histological characteristics that can lead to their identification. In most cases of AFP-gastric cancers, there is high rate of liver and lymph node metastasis [40]. No established correlation has been found between level of AFP and grade of malignancy [35]. It is reported that patients having AFP level greater than $300 \mathrm{ng} / \mathrm{ml}$ have less survival rate than patients having AFP level $<300 \mathrm{ng} / \mathrm{ml}$ [41]. There is not any standard therapy present for the treatment for AFP producing gastric cancer. Different therapies with reference to common cancer are given to patients in order to aid surgical outcome. However the level of AFP during treatment is regularly checked as its level decreases if effective treatment is carried out.

\section{AFP Role in Rectal Cancers}

AFP is also an important marker in case of rectal carcinoma. It is considered as one of the rare type of AFP producing cancers. Most of the extra hepatic cancers of AFP are usually present in stomach, pancreas and bile duct [17]. AFP producing colon and rectal cancers are not very common because they develop from hindgut instead of foregut. A small amount of AFP is produced by almost all cells of gastrointestinal tract. Although immunohistochemical features of AFP-rectal carcinoma are reported to be similar to AFP-gastric carcinomas but there is clear differentiation in histological characteristics of both type of cancers. It is reported that AFP cancers are more common in males and this change in prevalence is might be because of hormonal changes [42]. It is also reported that middle aged to older men having colorectal cancer have comparatively much higher level of AFP present in their serum (up to several thousand nanograms per $\mathrm{ml}$ ). Similarly patients having metastasis in liver also have higher level of AFP than patients without liver metastasis. Moreover, AFP appears to be a potential marker for tumor activity, as the serum level of AFP 
is higher in patients with liver metastasis than in those without liver metastasis [43]. Lymph node metastasis is also reported in some cases of AFP producing colorectal cancer. The observed frequency of lymph node metastasis in T1 stage of colorectal cancers is about $6-12 \%$ [44].

\section{AFP Based Cancer Treatment}

AFP has long been targeted for treatment of cancer by production of anti-cancerous drugs and antibodies. In women during third trimester of pregnancy, high level of AFP and its modified forms and peptide fragments are detected in body serum. Any previously present tumor's micro-foci present in mother breast tissues have shown growth suppression pattern in the presence of these AFP modified forms and peptide fragments (P149).

On basis of such observations AFP has been conjugated to a variety of anti-cancerous drugs such as calichemicin and vinblastine, which showed greater specific cytotoxicity than the drug alone. This AFP-drug conjugate made the drug more tumors specific, as tumor cells display AFP receptors more as compared to normal cells. This receptor based entry of drugs such as doxirubin into tumors via AFP helped to overcome the problems of drug resistance in ovarian and breast cancers in invitro cell lines [45].

Studies have been conducted to raise anti-AFP antibodies to suppress tumor growth. Hetrologous polyclonal anti-bodies were raised in rabbit and then injected in mice suffering from hepatomas, this showed reduction in level of mice serum AFP, both in in-vitro and in-vivo studies but tumor suppression was little achieved. However, it is a promising research field to treat cancers by generating antibodies against various factors and growth modulators of tumor cells.

Gene therapy approaches are also in their way to develop a therapeutic treatment against liver cancers using AFP gene. It deals with modulating AFP gene promoter, induction of suicide genes and making antisense of AFP [46,47].

\section{Conclusion}

We performed a literature review in order to discuss the diverse structural and functional properties of alpha-fetoprotein, one of the members of albuminoid protein family. A number of important functions of this protein include prenatal diagnosis to indicate fetal birth defects. Alpha-fetoprotein is potent biomarkers to study various malignancies and effect of various drugs on the tumors. AFP plays a dual role, that is, it acts as a growth mediator as well as growth suppressant of tumors. When secreted in serum it helps detecting the presence and site of tumors as they are tumor specific both qualitatively and quantitatively. Rectal carcinoma is considered as one of the rare type of AFP producing cancers. AFP producing colon and rectal cancers are not very common. The observed frequency of lymph node metastasis in T1 stage of colorectal cancers is about $6-12 \%$. AFPs have also been found associated with the regulation of cancer and angiogenesis in breast cancer and growth suppression in uterine and ovarian cancers. New biomedical approaches not only use AFP as a tumor detection tool but AFPs are exploited in potential treatment of cancers by conjugating them with various anti-cancerous drugs. Other treatment strategies include gene therapy and raising anti-AFP antibodies. The future of AFPs may be in the use of these glycoproteins in cancer therapies, diagnostics and other therapeutics.

\section{References}

1. European Association for the Study of the Liver, European Organisation for Research and Treatment of Cancer. EASLEORTC clinical practice guidelines: management of hepatocellular carcinoma. J Hepatol 2012; 56: 908-943.

2. Abelev G. This week's citation classic. Curr Contents 1987; 18.

3. Abelev GI. Alpha-fetoprotein in ontogenesis and its association with malignant tumors. Adv Cancer Res 1971; 14: 295-358.

4. Anzai H, Kazama S, Kiyomatsu T, Nishikawa T, Tanaka T, Tanaka J, Hata K, Kawai K, Yamaguchi H, Nozawa H, Kanazawa T, Ushiku T, Ishihara S, Sunami E, Fukayama M, Watanabe T. Alpha-fetoprotein-producing early rectal carcinoma: a rare case report and review. World J Surg Oncol 2015; 13: 180.

5. Ballas M. Yolk sac carcinoma of the ovary with alpha fetoprotein in serum and ascitic fluid demonstrated by immunoosmophoresis. Am J Clin Pathol 1972; 57: 511.

6. Beale G, Chattopadhyay D, Gray J, Stewart S, Hudson M, Day C, Trerotoli P, Giannelli G, Manas D, Reeves H. AFP, PIVKAII, GP3, SCCA-1 and follisatin as surveillance biomarkers for hepatocellular cancer in non-alcoholic and alcoholic fatty liver disease. BMC Cancer 2008; 8: 1.

7. Bei R, Mizejewski GJ. Alpha fetoprotein is more than a hepatocellular cancer biomarker: from spontaneous immune response in cancer patients to the development of an AFP-based cancer vaccine. Curr Mol Med 2011; 11: 564-581.

8. Bourreille J, Metayer P, Sauger F, Matray F, Fondimare A. Existence of alpha feto protein during gastric-origin secondary cancer of the liver. Presse Med 1970; 78: 1277-1278.

9. Bruix J, Sherman M, Llovet JM, Beaugrand M, Lencioni R, Burroughs AK, Christensen E, Pagliaro L, Colombo M, Rodes J. Clinical management of hepatocellular carcinoma. Conclusions of the Barcelona-2000 EASL Conference. European Association for the Study of the Liver. J Hepatol 2001; 35: 421-430.

10. Bruix J, Sherman M, Practice Guidelines Committee, American Association for the Study of Liver Diseases. Management of hepatocellular carcinoma. Hepatology 2005; 42: 1208-1236.

11. Chen DS, Sung JL, Sheu JC, Lai MY, How SW, Hsu HC, Lee CS, Wei TC. Serum alpha-fetoprotein in the early stage of human hepatocellular carcinoma. Gastroenterology 1984; 86: 1404-1409. 
12. Chun H, Kwon SJ. Clinicopathological characteristics of alpha-fetoprotein-producing gastric cancer. J Gastric Cancer 2011; 11: 23-30.

13. Festin SM, Bennett JA, Fletcher PW, Jacobson HI, Shaye DD, Andersen TT. The recombinant third domain of human alpha-fetoprotein retains the antiestrotrophic activity found in the full-length molecule. Biochimica et Biophysica Acta (BBA)-General Subjects 1999; 1427: 307-314.

14. Geuskens M, Torres J, Esteban C, Uriel J. Morphological characterization of the pathway of endocytosis and intracellular processing of transferrin and alpha-fetoprotein in human $\mathrm{T}$ lymphocytes stimulated with Phytohemagglutinin (PHA). Eur J Cell Biol 1989; 50: 418-427.

15. Goncharova O, Dudich E, Semenkova L, Gorbatova E, Dudich I. Synergy of alpha-fetoprotein and estradiol in suppression of tumor cell growth. Tumor Biol 1999; 20: 42.

16. Gonda T, Ishida H, Higuchi T, Hirukawa $H$, Nakajima $H$, Hojo I, Mishima Y. A case of AFP (alpha-fetoprotein) producing gastric cancer successfully treated with EAP (etoposide, adriamycin, cisplatin) therapy. Gan To Kagaku Ryoho 1994; 21: 1659-1663.

17. Harper ME, Dugaiczyk A. Linkage of the evolutionarilyrelated serum albumin and alpha-fetoprotein genes within q11-22 of human chromosome 4. Am J Hum Genet 1983; 35: 565 .

18. Khien VV, Mao HV, Chinh TT, Ha PT, Bang MH, Lac BV, Hop TV, Tuan NA, Don LV, Taketa K, Satomura S. Clinical evaluation of lentil lectin-reactive alpha-fetoprotein-L3 in histology-proven hepatocellular carcinoma. Int $\mathrm{J}$ Biol Markers 2001; 16: 105-111.

19. Korporaal SJ, Van Eck M, Adelmeijer J, Ijsseldijk M, Out $\mathrm{R}$. Platelet activation by oxidized low density lipoprotein is mediated by CD36 and scavenger receptor-A. Arterioscler Thromb Vasc Biol 2007; 27: 2476-2483.

20. Kurihara K, Konishi F, Kanazawa K, Fujii T, Saito K. Alpha-fetoprotein-producing carcinoma of the colon: report of a case. Surg Today 1997; 27: 453-456.

21. Laderoute MP, Pilarski LM. The inhibition of apoptosis by alpha-fetoprotein (AFP) and the role of AFP receptors in anti-cellular senescence. Anticancer Res 1994; 14: 2429-2438.

22. Li XD, Wu CP, Ji M, Wu J, Lu B, Shi HB, Jiang JT. Characteristic analysis of alpha-fetoprotein-producing gastric carcinoma in China. World J Surg Oncol 2013; 11: 246.

23. Lin HJ, Hsieh YH, Fang WL, Huang KH, Li AF. Clinical manifestations in patients with alpha-fetoprotein-producing gastric cancer. Curr Oncol 2014; 21: 394-399.

24. Liu X, Cheng Y, Sheng W, Lu H, Xu Y, Long Z, Zhu H, Wang Y. Clinicopathologic features and prognostic factors in alpha-fetoprotein-producing gastric cancers: analysis of 104 cases. J Surg Oncol 2010; 102: 249-255.

25. Lutsenko SV, Feldman NB, Finakova GV, Gukasova NV, Petukhov SP. Antitumor activity of alpha fetoprotein and epidermal growth factor conjugates in vitro and in vivo. Tumour Biol 2000; 21: 367-374.

26. McIntire KR, Waldmann TA, Moertel CG, Go VL. Serum alpha-fetoprotein in patients with neoplasms of the gastrointestinal tract. Cancer Res 1975; 35: 991-996.

27. Mehlman DJ, Bulkley BH, Wiernik PH. Serum alpha-1fetoglobulin with gastric and prostatic carcinomas. N Engl J Med 1971; 285: 1060-1061.

28. Meng WS, Butterfield LH, Ribas A, Heller JB, Dissette VB, Glaspy JA, McBride WH, Economou JS. Fine specificity analysis of an HLA-A2. 1-restricted immunodominant $\mathrm{T}$ cell epitope derived from human afetoprotein. Mol Immunol 2000; 37: 943-950.

29. Miyazaki J, Endo Y, Oda T. Lectin affinities of alphafetoprotein in liver cirrhosis, hepatocellular carcinoma and metastatic liver tumor. Acta Hepatol Jpn 1981; 22: 1559-1568.

30. Mizejewski G. Mapping of structure-function peptide sites on the human alpha-fetoprotein amino acid sequence. Atlas Genet Cytogenet Oncol Haematol 2009; 1-65.

31. Mizejewski GJ. Biological role of alpha-fetoprotein in cancer: prospects for anticancer therapy. Expert Rev Anticancer Ther 2002; 2: 709-735.

32. Mizejewski GJ, MacColl R. Alpha-fetoprotein growth inhibitory peptides: potential leads for cancer therapeutics. Mol Cancer Ther 2003; 2: 1243-1255.

33. Mizejewski GJ. Biological roles of alpha-fetoprotein during pregnancy and perinatal development. Exp Biol Med 2004; 229: 439-463.

34. Mizejewski GJ. Review of the putative cell-surface receptors for alpha-fetoprotein: identification of a candidate receptor protein family. Tumor Biol 2011; 32: 241-258.

35. Okita K, Noda K, Kodama T, Takenami T, Fukumoto Y, Fujii R, Odawara M, Iida Y, Hayakawa M, Shigeta K, Okazaki Y, Takemoto T. Carcino-fetal proteins and gastric cancer: the site of alpha-fetoprotein synthesis in gastric cancer. Gastroenterol Jpn 1977; 12: 400-406.

36. Parkin DM, Bray F, Ferlay J, Pisani P. Global cancer statistics, 2002. CA Cancer J Clin 2005; 55: 74-108.

37. Pucci P, Siciliano R, Malorni A, Marino G, Tecce MF, Ceccarini C, Terranna B. Human. alpha-fetoprotein primary structure: a mass spectrometric study. Biochemistry 1991; 30: 5061-5066.

38. Sun N, Sun Q, Liu Q, Zhang T, Zhu Q, Wang W, Cao M, Zang QI. alpha-fetoprotein-producing gastric carcinoma: A case report of a rare subtype and literature review. Oncol Lett 2016; 11: 3101-3104.

39. Tatarinov I. Content of the embryo-specific alpha-globulin in the serum of the fetus, newborn infant and adult man with primary liver cancer. Vopr Med Khim 1965; 11: 20-24.

40. Tateishi R, Yoshida H, Matsuyama Y, Mine N, Kondo Y, Omata M. Diagnostic accuracy of tumor markers for hepatocellular carcinoma: a systematic review. Hepatol Int 2008; 2: 17-30.

41. Terentiev AA, Moldogazieva NT. Alpha-fetoprotein: a renaissance. Tumour Biol 2013; 34: 2075-2091. 
42. Torre J, Laborda J, Naval J, Darracq N, Calvo M, Mishal Z, Uriel J. Expression of alpha-fetoprotein receptors by human T-lymphocytes during blastic transformation. Mol Immunol 1989; 26: 851-857.

43. Torres JM, Darracq N, Uriel J. Membrane proteins from lymphoblastoid cells showing cross-affinity for afetoprotein and albumin. Isolation and characterization. Biochimica et Biophysica Acta Protein Struct Mol Enzymol 1992; 1159: 60-66.

44. Villacampa M, Moro R, Naval J, Failly-Crepin C, Lampreave F, Uriel J. Alpha-fetoprotein receptors in a human breast cancer cell line. Biochem Biophys Res Commun 1984; 122: 1322-1327.

45. Vollmer CM, Eilber FC, Butterfield LH, Ribas A, Dissette VB, Koh A, Montejo LD, Lee MC, Andrews KJ, McBride WH. $\alpha$-Fetoprotein-specific genetic immunotherapy for hepatocellular carcinoma. Cancer Res 1999; 59: 3064-3067.
46. Wepsic H. Alpha-fetoprotein: Its quantitation and relationship to neoplastic disease. Alpha-Fetoprotein, Laboratory Procedures and Clinical Applications. Masson Publishing New York 1981; 115.

47. Yachida S, Fukushima N, Nakanishi Y, Akasu T, Kitamura H. Alpha-fetoprotein-producing carcinoma of the colon: report of a case and review of the literature. Dis Colon Rectum 2003; 46: 826-831.

\section{*Correspondence to}
Aleena Sumrin
Centre for Applied Molecular Biology
University of the Punjab
Pakistan 